\title{
1 Introduction to the Economic, Financial, Political and Legal Implications of Global Pandemics
}

"We shall require a substantially new way of thinking if mankind is to survive."
Albert Einstein

In this chapter, we begin with an assessment of the risks posed by fast-moving global pandemics. We then examine the origin and nature of the slow-moving global HIV/AIDS pandemic. The remainder of this chapter summarizes the topics that will be covered in the subsequent chapters of this book.

\subsection{The Threat of Global Pandemics}

In the summer of 2007, researchers from the University of Washington confirmed for the first time that the H5N1 influenza virus had been transmitted from human to human. A woman on the Indonesian island of Sumatra caught the virus from poultry in May of 2006 and transmitted the virus to her 10-year-old nephew, which was then transmitted to other relatives. Seven of eight family members who caught the disease died. This incident showed that there is a serious threat of an H5N1 influenza pandemic that could spread quickly and have a high and rapid mortality rate (Waters 2007). Human-to-human transmission of the H5N1 influenza virus was also suspected in Pakistan in November 2007 (McPherson 2007). The World Health Organization (WHO) uses six phases of pandemic alert to estimate the level of a threat. In December 2007, H5N1 was in phase 3, because it is a new influenza virus subtype that is causing disease in humans, but is not yet spreading efficiently and sustainably among humans. However, there is no way of knowing when such a pandemic might occur (Nebehay 2007). Figure 1.1 shows how often recorded influenza epidemics occurred during the second millennium, and how they have increased in frequency over time. This pattern is not surprising because fast-moving pandemics require close contact between groups of people. Over time, people began living together in bigger groups in cities. They also increased interactions due to faster modes of transportation.

The number of deaths of the next influenza pandemic could surpass the estimated 50-100 million deaths caused by the 1918-1919 global flu pandemic, commonly referred to as the Spanish Flu (Taubenberger and Morens 2006). The 1918-1919 influenza virus had a mortality rate of 2.5\%, significantly higher than previous influenza epidemics, which were less than $0.1 \%$ (Taubenberger and Morens 2006; Billings 1997). Moreover, unlike other flu pandemics, almost half of the influenza-related deaths were in young adults, 20-40 years of age (Taubenberger and Morens 2006). In this regard, the 1918-1919 virus was like HIV/AIDS, 
Recorded Influenza Pandemics 1100-1980

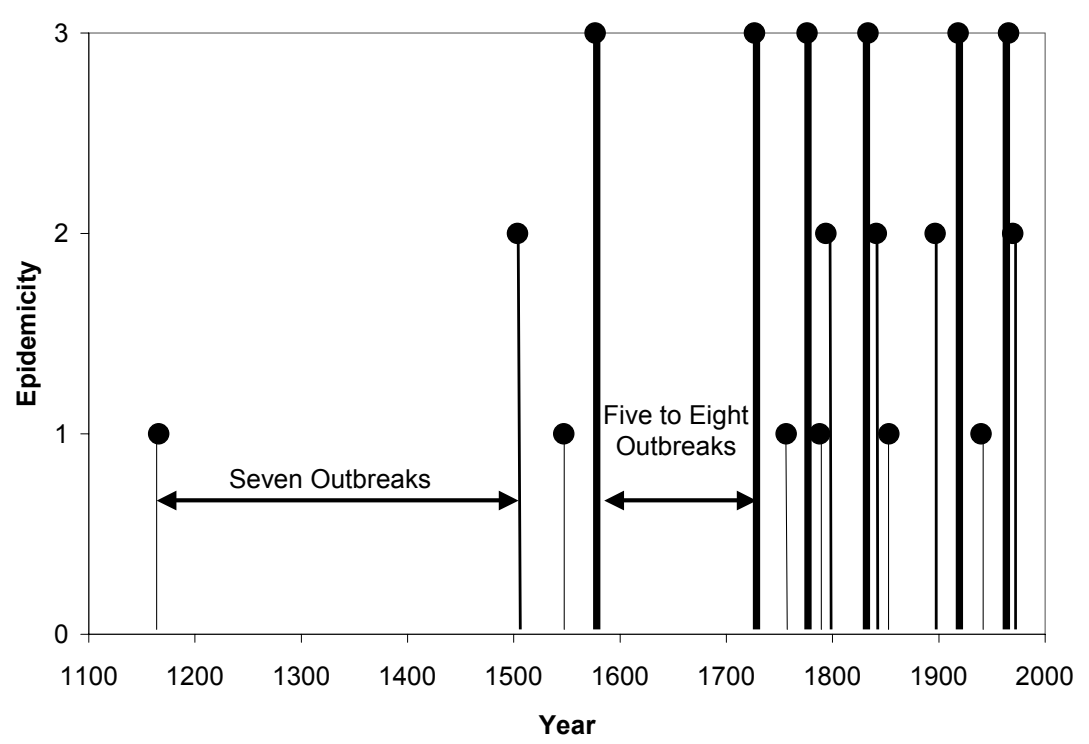

Fig. 1.1 Frequency and severity of influenza 1100-1980 AD. Notes: 1, epidemic; 2, probable pandemic; 3, pandemic. Source: Potter, C.W: Textbook of Influenza, Nicholson, Webster, Hay, Blackwell Science 1998

which also affects young adults in the most productive years of their lives and has a correspondingly greater economic impact.

The experience with HIV/AIDS mortality in South Africa (see Chap. 3) is a stark reminder of what happened during the Spanish Flu epidemic in the United States. Figure 1.2 reproduces the mortality experience in the United States during 1918 and compares it with the experience of the previous 7 years (1911-1917). Both the HIV/AIDS epidemic and the Spanish Flu epidemic have one important common element - they both affected adults. They did not affect the young and the old with weak immune systems, as had happened in the case of other epidemics like the plague in the fourteenth century. If the excess deaths occur mainly among the very young and the very old, the economic implications are different, since the young have not accumulated much human capital and society has not spent many resources on them yet. Similarly, if the very old die, they do not affect production in a society. However, when adults die in the prime of their productive years, it reduces economic growth significantly.

The reason that HIV/AIDS affects mostly adults is reasonably clear - it is largely a sexually transmitted disease. While mother-to-child transmission, transmission by contaminated needles and transmission through blood transfusion make it possible to see the impact on other age groups, the bulk of HIV transmission is still due to sexual contact. 
Spanish Flu Effect

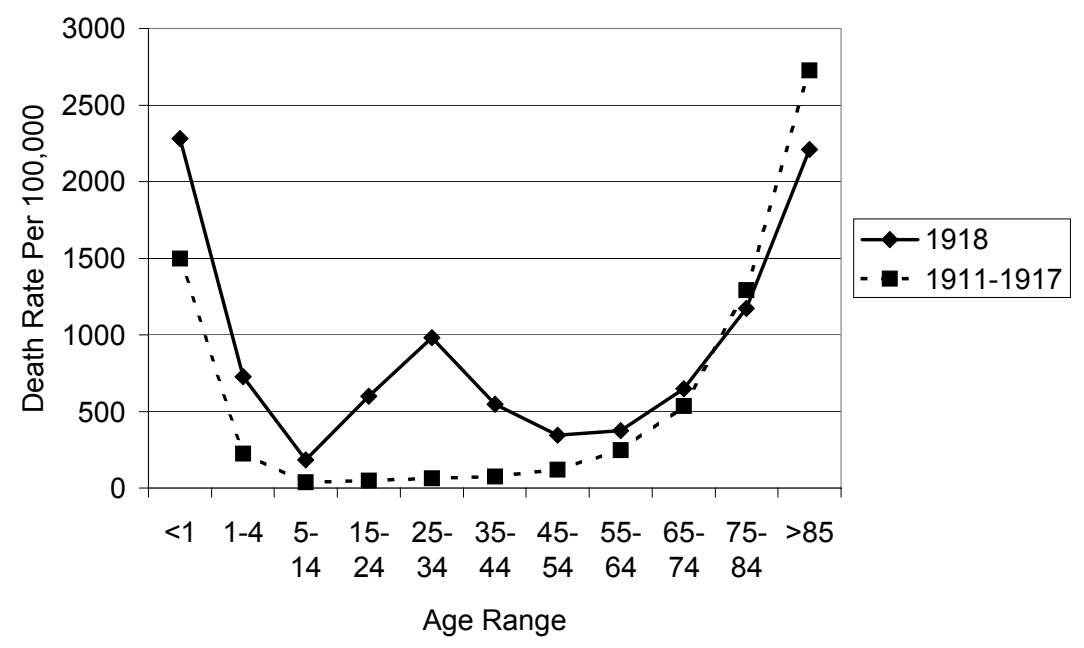

Fig. 1.2 Rising mortality due to Spanish Flu. Source: CDC Data

It is still unclear why the Spanish Flu affected the most able-bodied persons at a higher rate. One plausible hypothesis is that the flu itself was not the cause of their deaths. Rather, the virus produced a reaction that caused the patients' own organs to attack the body. Since able-bodied persons have the most vigorous organs, they were affected the most. It is also important to remember that the Spanish Flu was not identified as flu until more than a decade later. Thus, most of what we know today about the Spanish Flu is the result of postmortem analysis of the disease.

The one striking difference between the increases in mortality in these two pandemics was time. In the case of the Spanish Flu, the impact was swift. Everything happened within a span of 3 years. In the case of HIV/AIDS, the impact has unfolded over decades (see Fig. 1.3).

Like the 1918-1919 virus, H5N1 is an avian virus (Taubenberger and Morens 2006). The 1918-1919 influenza virus spread along trade routes and shipping lines, along with the frontlines of World War I (Billings 1997). A century later, what might the impact of such a fast-moving virus be? Trade routes have increased dramatically, as have the means for transporting humans around the globe. Figure 1.4 shows the dramatic increase in global airline traffic in the second half of the twentieth century. These factors suggest that an H5N1 influenza pandemic could unfold much more rapidly and cause many more deaths than the 1918-1919 pandemic.

The evolution of science and international institutions over the past century are mitigating factors that could help to contain the effects of a fast-moving global 
Worldwide Prevalence (Revised Estimate) 1982-2007

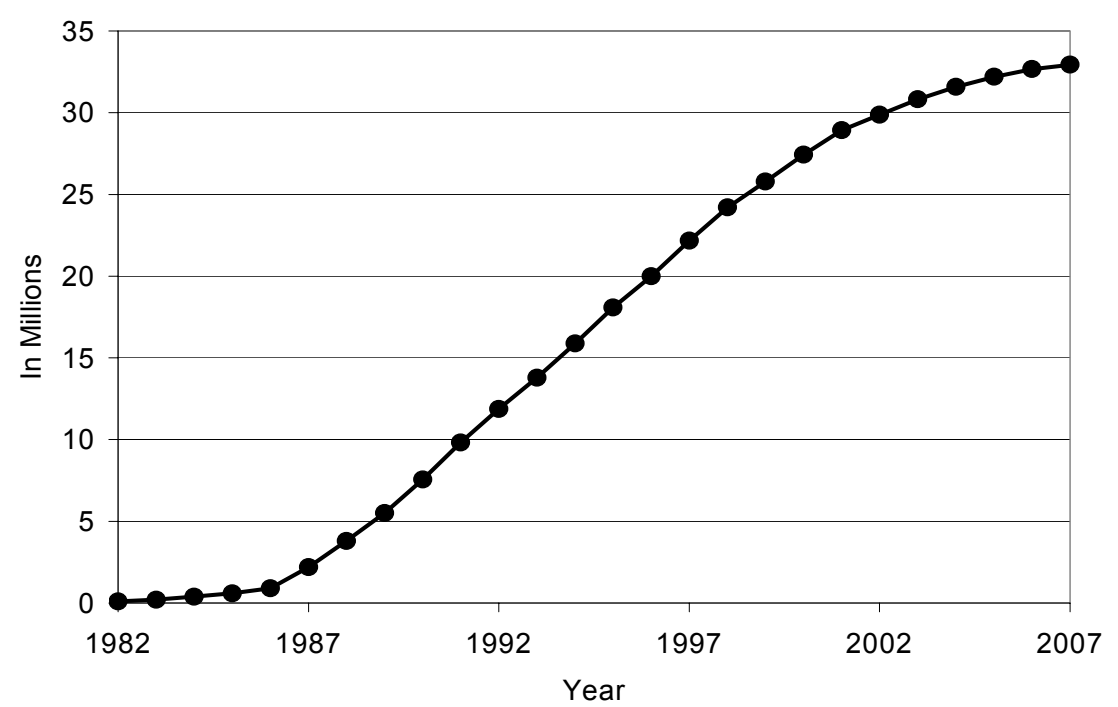

Fig. 1.3 Increasing worldwide prevalence of HIV/AIDS. Source: UNAIDS, Avert.org, and own calculations

International Airline Passengers 1950-2000

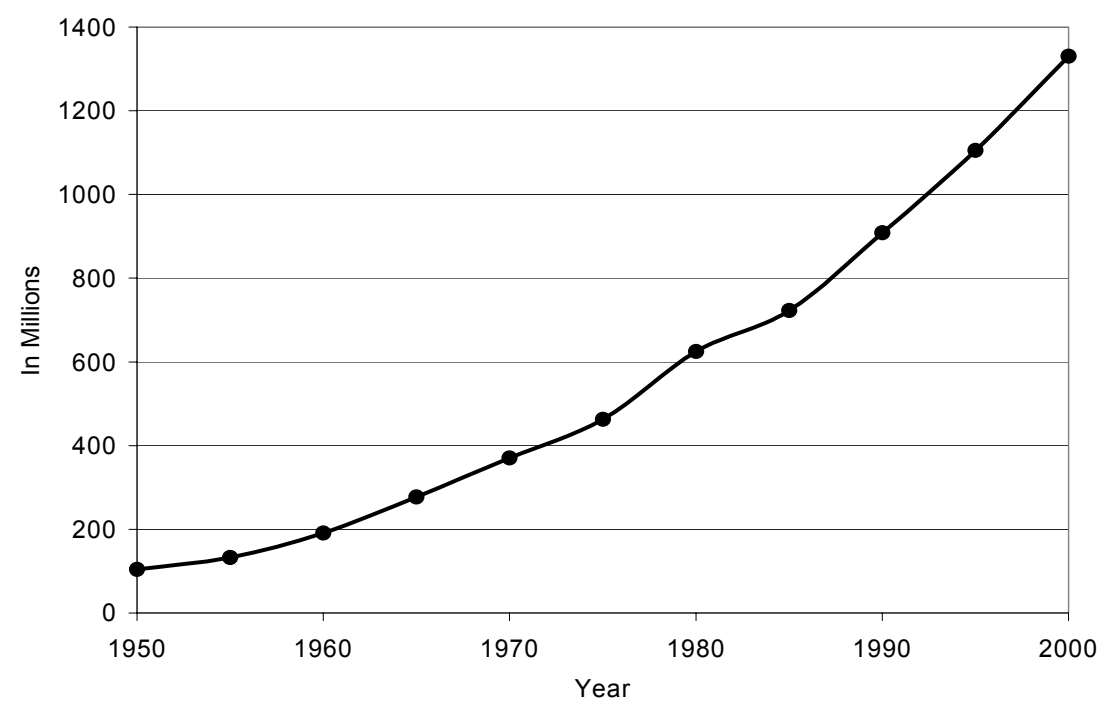

Fig. 1.4 Global airline traffic 1950-2000. Source: World Health Organization and World Tourism Organization 
pandemic in the twenty-first century. However, as the experience with severe acute respiratory syndrome (SARS) showed, modern air travel means that contagious diseases can spread rapidly around the globe (see Fig. 1.5). Even with modern antiviral and antibacterial drugs, vaccines, and prevention knowledge, the return of a pandemic virus equivalent to the virus of 1918-1919 would probably kill more than 100 million people worldwide, and a pandemic virus with the pathogenic potential of the H5N1 virus could cause substantially more deaths (Taubenberger and Morens 2006).

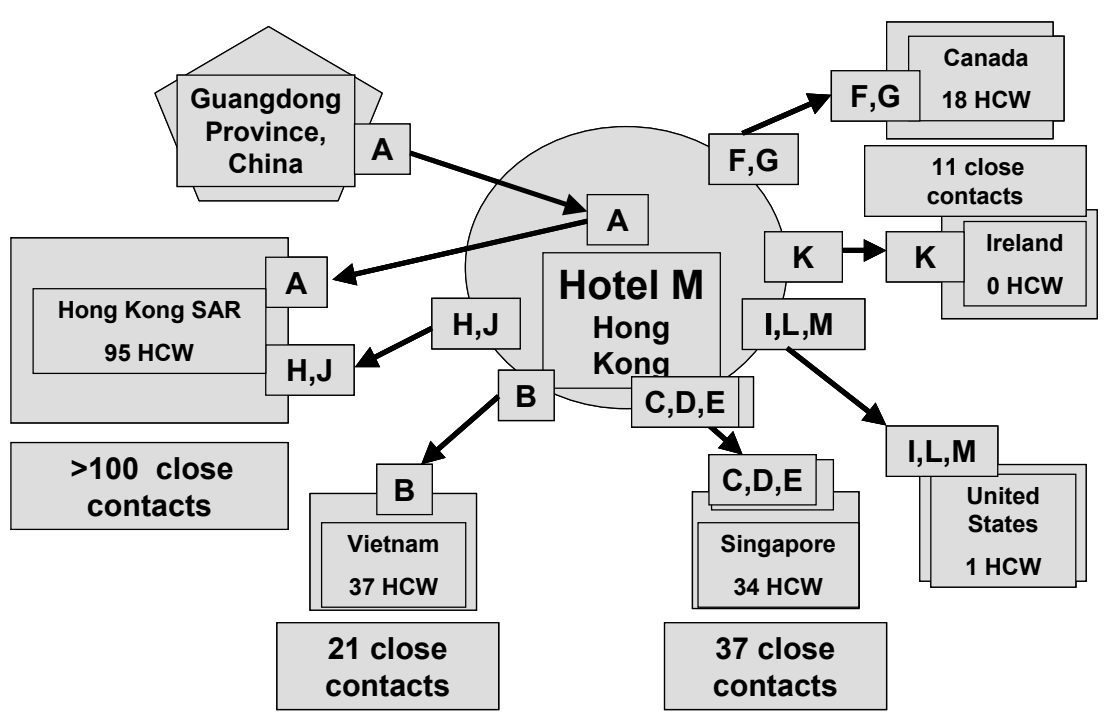

Source: WHO/CDC, HCW stands for healthcare workers

Fig. 1.5 International amplification and transmission of SARS by guests at Hotel M, Hong Kong, 21 February-26 March. Source: WHO and CDC

Globalization, together with global climate change, also means that diseases that were formerly confined to tropical developing countries are now spreading to temperate developed countries. This is occurring through a combination of vector migration - the movement of mosquitoes from the tropics to temperate regions and human travel. West Nile virus, which is transmitted by mosquitoes, is now found throughout the continental United States and Canadian provinces. Chikungunya, a tropical disease that is related to dengue fever, is normally found in the Indian Ocean region. However, in the summer of 2007, a chikungunya epidemic occurred in northern Italy, where tiger mosquitoes now can thrive in the warming climate of southern Europe. An Italian, who had traveled to Kerala, India, returned to Italy with chikungunya in his blood, where it was spread by the tiger mosquitoes. This was the first epidemic of a tropical disease in a developed, European 
country in modern times (Rosenthal 2007). The movement of developing country diseases to developed countries provides another reason to view developing country diseases, which have been largely neglected, as a global problem that requires a global response.

Infectious diseases can also originate in developed countries. In November 2007, a new and virulent strain of adenovirus was reported in parts of the United States. The US Centers for Disease Control and Prevention (CDC) reported that two of the ten people who died from the new strain were infants and 50 of the 140 affected people were hospitalized, including 24 admitted to intensive care units. The new strain of adenovirus first appeared in May 2006 in New York, and spread to Oregon, Washington state and Texas. This particular adenovirus can make healthy young adults severely ill, which is unusual for an adenovirus (Dunham 2007).

Understanding past outbreaks of diseases can lead to new public health measures and other interventions to more effectively address existing diseases and to better prepare the world for future diseases. Sherman (2007) has examined how several diseases have influenced society, politics and culture and spawned new ways to address diseases and their consequences: (1) porphyria and hemophilia, which affected the royal families of Europe, influenced the political fortunes of England, Germany, Russia and the United States; (2) late blight, which caused the Irish potato famine in the 1850s, led to a wave of immigration that changed the politics of the United States; (3) cholera, which prompted sanitary measures, promoted nursing and led to the discovery of oral rehydration therapy; (4) smallpox led to a vaccine that eradicated the disease; (5) bubonic plague, which caused the "Black Death" in the fourteenth century, promoted quarantine measures; (6) syphilis led to a cure through chemotherapy; (7) tuberculosis led to attenuated vaccines; (8) malaria and yellow fever provided the basis for vector control; and (9) influenza and HIV/AIDS, two pandemics that continue to challenge humanity.

The main focus of this book is the AIDS pandemic - a slow-moving global pandemic with a high mortality rate. This slow-moving pandemic has revealed some of the flaws in our international economic, financial, legal and political institutions and provides many lessons on how to improve the ways that the world addresses global diseases. Unlike other diseases that disproportionately affect developing countries, HIV/AIDS has not been neglected because it also affects developed countries. This chapter begins with a brief description of the origins and nature of the HIV virus, then provides an overview of the issues that will be analyzed in this book.

\subsection{The Origins of the HIV Virus}

There are two major groups of HIV viruses: HIV-1 and HIV-2. HIV is a lentivirus that attacks the immune system. "Lentivirus" literally means a slow virus, thus 
named because of the time it takes to produce any adverse effect on the body. Lentiviruses are in turn part of a larger group of viruses known as retroviruses. Retroviruses have been found in a number of different animals, including cats, sheep, horses, monkeys and cattle.

There is evidence that the origin of HIV is the Simian Immunodeficiency Virus (SIV), which affects monkeys. Scientists believe that HIV is a descendant of SIV because certain strains of SIV bear a very close resemblance to HIV-1 and HIV-2. The more virulent strain of HIV, HIV-1, is the closest to SIVcpz, the SIV strain found in chimpanzees. Nevertheless, this virus is still significantly different from HIV. HIV-2 corresponds to SIVsm, a strain of SIV found in the sooty mangabey (also known as the green monkey). This monkey is indigenous to western Africa (Gao et al., 1999).

There are several theories about how zoonosis (the process by which a virus is transferred between animals and humans) caused SIV to mutate into HIV. The most commonly accepted theory is the "hunter" theory. According to this theory, SIVcpz was transferred to humans when hunters killed and ate chimpanzees or when the chimpanzee's blood infected the hunters' cuts or wounds. Most of the time, the hunter's body would have fought off SIV. However, in a few instances, SIV would adapt to its new human host to become HIV-1. This "hunter" theory finds support in the existence of several different early strains of HIV, each with a slightly different genetic make-up (with the most common strain being HIV-1 group M). Every time the virus passed successfully from a chimpanzee to a human, it would develop in a slightly different way and thus produce a slightly different strain (Wolfe et al., 2004).

Although clear cases of AIDS were identified in the early 1980s in the United States, a plasma sample taken in 1959 from an adult male living in what is now the Democratic Republic of Congo showed the presence of HIV-1 (Zhou et al., 1998). Similarly, HIV-2 seems to have come from Guinea-Bissau. By analyzing samples of two different subtypes of HIV-2 (A and B) taken from infected humans and SIV samples taken from sooty mangabeys, Vandamme et al. (2003) concluded that both subtypes A and B had passed into humans in the 1950s (with a margin of error of 15 years). It is entirely possible that transmission from monkeys to humans had occurred decades, or even centuries, earlier. However, if groups of infected humans did not come into close contact with other groups, they might have died out.

\subsection{The Nature of HIV/AIDS}

HIV destroys the human immune system, leaves millions of adults vulnerable to a wide range of lethal illnesses in the prime of their life and kills millions of children whose lives have barely begun. HIV enters the human body via fluids such as blood or semen, attaches itself to the infection-fighting CD4 cells of the immune system, injects its RNA into the DNA of the host CD4 cells and then uses the CD4 
cell's division mechanism to replicate. These copies of HIV then enter the blood stream, attach themselves to other CD4 cells and continue replicating. Over time, the quantity of HIV in the blood increases and the number of CD4 cells decreases. Some people begin to have symptoms within months, while others can be without symptoms for more than 10 years. However, the virus continues to multiply, infecting and killing the cells of the immune system, and can be transmitted to other people through unprotected sex, blood transfusions or organ transplants and the sharing of needles, even though the infected person has no symptoms.

When the immune system is sufficiently weakened, it is no longer able to fight off infections caused by common bacteria, virus, fungi and parasites, such as: mycobacterium avium complex (which causes night sweats, weight loss, abdominal pain, fatigue, diarrhea and anemia); tuberculosis (which causes night sweats, weight loss, loss of energy, poor appetite, fever and a cough), salmonellosis (which causes diarrhea, fever and abdominal pain and cramps); bacillary angiomatosis (which causes skin lesions and can affect internal organs, including the brain, bone marrow, heart, lungs, larynx, tongue, esophagus, stomach, colon, diaphragm, kidneys, adrenal glands, pancreas, uterine cervix and vulva); cyto-megalovirus (which can cause fever, fatigue, rash, chills, fatigue, headache and blindness); viral hepatitis (which can cause loss of appetite, nausea, vomiting, fever, weakness, fatigue and aching in the abdomen); herpes (which can cause painful blisters, headache, muscle ache and fever); human papillomavirus (which can cause genital warts and pre-cancerous changes in the cervix, vulva, anus or penis); progressive multifocal leukoencephalopathy (which can cause mental deterioration, vision loss, speech disturbances, a loss of coordination, paralysis and coma); candidiasis (which can cause burning pain in the mouth or throat, pain and difficulty when swallowing and vaginal yeast infections); cryptococcal meningitis (which can cause severe headache, nausea, vomiting, blurred vision, sensitivity to bright light, stiff neck, seizures, confusion, behavioral changes and coma); pneumocystis carinii pneumonia (which can cause fever, chest tightness, shortness of breath, lack of energy, dry cough and weight loss); toxoplasmosis (which can cause damage to the brain, eyes or other organs); and cryptosporidiosis (which can cause diarrhea, dehydration, weight loss, stomach cramps or pain, fever, nausea and vomiting). HIV-positive people can also get cancers, such as Kaposi's sarcoma (which can cause lesions on the skin, mouth, throat, lungs and the intestinal tract) and lymphoma (which can cause fever, chills, weight loss, night sweats and lack of energy).

HIV treatment involves the use of antiretroviral drugs that prevent the virus from replicating, thereby reducing the amount of virus in the body. However, these drugs do not eliminate the virus from the body and become ineffective if the virus mutates and develops resistance to the drugs. Drug resistance is delayed by using two or more classes of anti-HIV drugs in combination, each of which attacks the virus in a different way. Other medical interventions focus on preventing or treating the opportunistic infections listed above. We examine HIV/AIDS treatment issues in greater detail in Chaps. 3 and 9. 


\subsection{HIV/AIDS Strategies in Developed and Developing Countries}

In Chap. 2, we provide an overview of the global AIDS pandemic and the three central issues that form part of a comprehensive AIDS strategy - prevention, treatment and human rights protection. Each of these issues is inter-related and must be considered in the context of specific countries or regions, in order to take into account variations in cultural values, affected groups, infection rates, legal systems, economic resources and human resources. Chapter 2 therefore analyzes these key issues in country-specific and region-specific contexts. Prevention, treatment and human rights protection also raise other issues, such as the cost of patented medicine, the right of governments to suspend patent rights and the use of litigation and international political pressure to increase the cost of life-saving medicines.

In 2007, there were an estimated 30.6-36.1 million people living with HIV/AIDS worldwide, 1.8-4.1 million new infections and 1.9-2.4 million people dying from AIDS-related illnesses. HIV/AIDS disproportionately affects the most marginalized groups in each society - the poor, commercial sex workers, men who have sex with men, injection drug users and women. However, the degree to which these groups are marginalized varies from one society to the next and within each society. As a sexually transmitted disease, the stigma associated with AIDS further isolates the people who live with this condition and makes HIV difficult to discuss openly. Widespread societal taboos regarding sex, negative attitudes regarding the groups of people most affected by the virus and the fear that is kindled by infectious disease have proved to be powerful allies for a virus whose transmission would be otherwise more easily prevented. The stigma associated with HIV/AIDS and a lack of legal protection against discrimination may deter people from seeking testing and treatment. The lack of access to treatment and information also can discourage people from seeking testing, which in turn can contribute to the spread of the disease. Moreover, antiretroviral treatment reduces the amount of HIV in the body, thereby reducing the risk of transmission.

The course of the HIV/AIDS pandemic in different settings underlines the importance of early intervention with appropriate policies to prevent and contain the spread of global diseases. The source of HIV/AIDS in animals and its transmission to humans through zoonosis shows that the world community needs to be vigilant regarding other such events. For example, H5N1 influenza, which is a more infectious disease, would spread much more rapidly than HIV/AIDS. In order to prepare for such a pandemic, the lessons of the HIV/AIDS pandemic would have to be applied before the pandemic occurs. The HIV/AIDS epidemic in Africa has demonstrated how health issues can become security issues. It has also demonstrated the importance of political leadership and accurate information in containing the spread of disease.

The experience in Brazil and Thailand indicate that a well-designed HIV/AIDS program that is tailored to the specific epidemic and to the specific context of the 
country in question can be successful, at least in middle-income countries with relatively low prevalence rates. The lesson from Brazil and Thailand is not that other countries should duplicate these two countries' programs. Rather, the lessons from Brazil and Thailand are that: (1) responses to HIV/AIDS need to be tailormade; (2) governmental and NGO leaders have a crucial role to play; (3) early intervention is necessary in order to contain the spread of the virus; and (4) health infrastructure and human resources need to be adequate.

The incorporation of a human rights program appears to be an important element that has contributed to Brazil's success. The stigma associated with HIV/AIDS in South Africa has hampered that country's efforts, whereas the relative absence of stigma surrounding the commercial sex trade in Thailand has meant the absence of such a barrier to action in that country. Similarly, the stigma associated with injection drug users in Russia hampered the implementation of an effective HIV/AIDS strategy in a country where injection drug users make up 50\% of the epidemic. Thus, social conditions may be highly relevant to the design of an effective HIV/AIDS program. Finally, the nature of the epidemic must be taken into account in each context. In both Brazil and Thailand, efforts have focused on high-risk groups, which differed in the two settings - with commercial sex workers being the main focus in Thailand and Brazil's efforts focused on men who have sex with men, injection drug users and commercial sex workers.

Providing universal access to antiretroviral therapy requires adequate financial resources in the face of a particular prevalence rate. The manner in which governments deal with negotiations with other governments and patent owners has a direct impact on the cost of treatment, as demonstrated by South Africa, Thailand and Brazil. However, financial resources do not necessarily correlate with the design of an effective program, as the case of Japan demonstrates. Moreover, even middle-income countries can face disaster where political leadership is replaced by inaction and denial, as the case of South Africa shows. Both the Japanese and the South African experiences demonstrate that cultural or psychological predispositions can hobble the capacity of a country to respond effectively to the threats posed by epidemics. These factors therefore need to be taken into account in the design of international responses to the threat posed by global diseases.

The difficulties faced by developing countries in confronting the HIV/AIDS epidemic have direct effects on the developed world. The HIV/AIDS pandemic has influenced World Trade Organization (WTO) policy regarding patent protection for pharmaceutical companies that are primarily located in the developed countries. In this regard, the epidemic has begun to change an important element of international economic policy. The migration of natural persons across the borders of an increasingly integrated global economy means developed country interests are also at stake in addressing the HIV/AIDS pandemic in developing countries. Borders do not prevent the spread of the virus and closing borders is not an option in a globalized world. Perhaps most significantly, national and global experiences with the HIV/AIDS pandemic provide lessons for addressing not just HIV/AIDS, but other global diseases and pandemics as well. A complete picture of the HIV/AIDS 
pandemic requires an analysis of its effects on human health, security, international relations, business, international economic policy, national economic growth and social dynamics. However, this multi-faceted analysis serves not only to ensure effective strategies for confronting this disease and this pandemic, but to underline the importance of a multidisciplinary approach to other global health issues.

\subsection{Insurance, Mortality, Treatment Costs and the Business Impact of HIV/AIDS}

In Chap. 3 we analyze financial aspects of HIV/AIDS. HIV/AIDS was first identified in developed countries, where the insurance industry was the first business to be deeply affected by HIV/AIDS. Later, HIV/AIDS became a financial issue for all industries offering health care for their employees, as well as governments concerned with public health expenditures. In developing countries, with a few exceptions like Thailand and Brazil, the reaction to HIV/AIDS was slower.

Chapter 3 focuses on the data and financial tools used by insurance companies to address the financial risks associated with the HIV/AIDS pandemic. We first examine these issues in the context of developed countries, focusing on the United States. We then examine these issues in the context of developing countries, focusing on high-prevalence countries in sub-Saharan Africa and, in particular, South Africa. We then consider public and private sector strategies that might be adapted to South Africa's situation. Finally, we demonstrate that the potential financial benefits to companies in high-prevalence countries from funding prevention and treatment programs for their employees are likely to exceed the costs of such programs.

In the early 1980s, the insurance industry in the developed world was concerned about the impact of HIV/AIDS, due to long-term, individual life insurance policies for which they could not deny renewal and due to their inability to identify and exclude persons with HIV from group insurance coverage. In the late 1980s, it appeared that AIDS would cause death within 2 years and that the number of cases would exceed 1.2 million by 1998 in the United States alone. This new risk not been priced into insurance premiums and might have threatened the solvency of many life insurance companies.

However, once the nature of HIV transmission was understood, prevention reduced the actual numbers. In addition, in 1996, the advent of triple combination antiretroviral treatments for HIV/AIDS reduced mortality significantly and dramatically increased the number of years people could live with HIV/AIDS. With a correct assessment of survival probabilities for HIV-positive individuals, insurance companies could accurately calculate the financial reserves they needed to set aside. These developments lowered the financial risks of having long-term life insurance policies on HIV-positive individuals. Moreover, the cost of the new treatments did not pose a threat to private health insurers, since most health insurance policies were renewable annually and could be factored into their premiums. 
In addition, by the late 1990s, it became possible to estimate the cost of treatment for HIV/AIDS. The result is that the insurance risks associated with HIV/AIDS are now similar to those for diabetes and can be priced accordingly.

In many developing countries the situation is very different, for the following reasons: (1) prevalence rates are much higher in many developing countries and vary widely; (2) HIV/AIDS has expanded beyond high-risk groups to the general population; (3) healthcare infrastructure is inadequate in many developing countries; and (4) mechanisms for estimating prevalence and tracking the spread of HIV/AIDS are less developed. For example, in 2007 a major revision of HIV/AIDS prevalence in India reduced the estimated number of cases from 5.7 million in 2004 to 2.47 million in 2006. The accuracy of HIV/AIDS estimates is important, both for governments involved in assessing the scale of prevention and treatment needs and for the private sector, particularly the insurance industry. The correct pricing of insurance products requires an accurate assessment of the frequency and severity of risks.

South Africa has the most HIV/AIDS cases in the world and one of the highest prevalence rates. Moreover, mortality rates are high and survival probabilities are low, due to a lack of access to treatment. However, the highly developed South African insurance industry was not severely affected by the dramatic rise in HIV/ AIDS prevalence in South Africa, because most life insurance policies in South Africa were short-term policies and South African insurance companies used income and education levels to categorize risk. However, while the insurance industry in South Africa has been able to survive HIV/AIDS, this has come at the cost of reduced access to life insurance and limited access to health insurance that might cover part of the cost of treatment for HIV/AIDS. Thus, while South Africa is a middle-income country, it has not achieved universal access to treatment for people living with HIV/AIDS. Achieving this goal in South Africa is further complicated by its high prevalence rate.

Mexico has expanded access to HIV/AIDS treatment primarily through the purchase of higher cost patented drugs. While both South Africa and Mexico are middle-income countries, there is a big difference in their HIV prevalence rates. This means that the Mexican approach would not be affordable in South Africa. While the Mexican public health insurance model could work in South Africa, the purchase of antiretroviral medication for South Africa would have to be funded by external sources. In addition, South Africa would have to pursue the same strategy as Thailand and Brazil, by substituting generic equivalents for more expensive patented drugs. However, for middle-income countries with prevalence rates like South Africa, expanding access to treatment for HIV/AIDS is likely to require a mixture of public and private sector strategies.

In the United States and other developed countries, a financial mechanism was developed to convert terminally ill patients' savings through life insurance into viatical settlements. Viatical settlement companies give cash to terminally ill patients in exchange for their life insurance policies. When the patient dies, the company collects the death benefits. This process enabled terminally ill patients to 
pay for medical treatment. In Chap. 3, we demonstrate that a properly regulated viatical market, combined with insurance regulation that provides access to life insurance for HIV-positive individuals, provides a mechanism to enhance private sector coverage of the cost of HIV treatment. A viatical market serves as a complement to coverage under a public health care system. However, unlike South Africa, the United States has a prevalence rate of below one percent and is a highincome country. Moreover, in South Africa there is no viatical market. Nevertheless, while South Africa is a middle-income country, it has the most developed insurance market in the world as a percentage of gross domestic product (GDP). In this regard, South Africa is different from most developing countries. Given the level of development in the South African insurance market, the development of a viatical market is a viable option for South Africa.

Viatical markets represent one example of a broader category of financial instruments, known as securitization. Securitization of mortality is a new financial mechanism that can be used to hedge against the risk of a fast-moving epidemic, such as influenza. The loss of life and health care costs of such a pandemic could be catastrophic for life and health insurance companies. Securitization can be used to insure otherwise unmarketable risks and thereby reduce the financial risks of insurance companies. It is also a way to expand life and health insurance coverage to the risk of a serious, fast-moving pandemic. However, securitization only works where there is a low probability of such a high-loss event occurring. For this reason, it is unlikely to work in the case of HIV/AIDS in countries with high prevalence, since this is no longer a low probability event in those countries.

\subsection{The Economics of HIV/AIDS}

In Chap. 4, we use macroeconomic and microeconomic analysis to examine how economic conditions affect HIV/AIDS and how HIV/AIDS affects economic development. We examine the relationships between HIV/AIDS and poverty, inequality and social capital, and consider whether economic differences between countries explain differences in HIV prevalence. Since HIV/AIDS disproportionately affects people of working age, we use a macroeconomic model to examine the potential economic impact of HIV/AIDS. We show how microeconomic and epidemiological models about behavioral responses to HIV/AIDS can help to determine the effectiveness of specific HIV/AIDS prevention strategies. Economics plays a significant role in the propagation of HIV/AIDS in high incidence countries. The economics of HIV/AIDS also shows us the likely economic returns on actions that prevent HIV infections.

There is evidence that the substantial difference in the transmission rates between the United States and sub-Saharan Africa are due to untreated bacterial sexually transmitted infections. One implication of this evidence is that expanding treatment of other sexually transmitted infections may prove to be a cost effective way to reduce the incidence of HIV/AIDS. Another implication is that lower 
levels of economic development are not necessarily the root cause of higher rates of HIV/AIDS prevalence or vice versa. Another variable, such as war, inadequate health or poor education, may explain the relationship between poverty and HIV/AIDS. While there is a significant negative correlation between social capital and income inequality, on the one hand, and HIV/AIDS, on the other hand, it is not clear what policy prescription should flow from these findings. Reducing income inequality by taxation and redistribution of wealth can negatively affect individual incentives and the policies that might increase social capital are not obvious. Poverty reduction is too broad a goal to constitute what might be termed an HIV/AIDS prevention strategy. Moreover, there is no clear evidence that reducing poverty and income inequality will necessarily reduce HIV/AIDS prevalence.

It is difficult to predict the impact of HIV/AIDS on economic development. In theory, rising HIV/AIDS prevalence could cause the labor participation rate to rise, to fall or to remain the same. Rising rates of HIV/AIDS would reduce the supply of labor, but would also reduce the population. If HIV/AIDS were to reduce the supply of labor and the population to the same degree, then labor per capita would remain the same. Since HIV/AIDS strikes the population at a productive age, it may reduce the labor force more than the entire population, and the labor participation rate would fall. However, a decline in the supply of labor would lead to a rise in capital per labor unit in the short run. Nevertheless, in the long run, the supply of capital may fall if rising HIV/AIDS leads to less saving and investment.

Falling life expectancy and rising mortality due to HIV/AIDS may lead to lower future economic growth due to the importance of human capital for long-term accumulation of wealth. On the societal level, an HIV/AIDS epidemic can affect the size, growth rate and age and skill composition of the future labor force. In addition, the slow-moving nature of HIV/AIDS produces higher costs of treatment and palliative care than epidemics that kill quickly. These additional costs can decrease GDP growth by reducing savings and investment. On the individual level, HIV/AIDS can reduce income and increase costs. The diminished working capacity of individuals with HIV/AIDS reduces income and lower life expectancy reduces lifetime income. Higher costs, such as medical expenses and caring for orphans, lead to less education for children and lower savings. HIV/AIDS destroys human capital in a number ways and reduces the transmission of human capital between generations, leading to declining levels of education. However, it is difficult to determine the impact of HIV/AIDS on all macroeconomic variables. For example, rising incidence of HIV/AIDS can lead to rising or falling total fertility rates, which also affect human capital and economic growth. As a result, the impact of HIV/AIDS on overall economic welfare, in the form of changes to GDP, remains unclear.

Microeconomic and epidemiological models in Uganda show that promoting sexual abstinence before marriage and monogamy are less effective HIV/AIDS prevention strategies than condom promotion. Moreover, behavioral responses to HIV/AIDS risk depend on life expectancy. Individuals with higher incomes and longer life expectancy are more likely to respond to HIV risk. In regions in Africa 
with high rates of malaria, people already face a high risk of death from malaria and have little incentive to change their sexual behavior. Reducing the risk of death from malaria would increase incentives to change sexual behavior to reduce HIV risk. The reduction of malaria risk is relatively inexpensive, making malaria prevention a cost effective way to reduce HIV risk.

Evidence from Uganda regarding the connection between exports and HIV suggests that targeting prevention at vulnerable groups would be an effective strategy in generalized HIV epidemics. Increased exports lead to increased transportation of goods and more people movement. Truckers and other migrants are important drivers of the overall epidemic, which means that targeting prevention activities at that group would decrease HIV transmission. In addition, if increases in economic activity make the HIV epidemic worse, economic growth strategies need to incorporate HIV prevention strategies.

Another economic issue raised by HIV/AIDS is the side-effect of large increases in foreign aid to combat HIV/AIDS in high-prevalence, low-income countries. Where foreign aid increases the money supply, inflation may rise and the balance of payments may deteriorate. Large inflows of resources could significantly raise the real value of the local currency, thereby producing low economic growth, increased international debt, higher imports and lower exports. Additional expenditures would raise the wages of skilled professionals, making the private sector less competitive in the long run. The economy would become significantly more dependent on aid and remain that way for the indefinite future. Thus, foreign aid is not an unmitigated blessing.

Another question is whether we can justify singling out HIV/AIDS for increased funding when lives could be saved in other, less expensive programs. For example, prevention programs targeted at sexual transmission and transmission among injection drug users could avert 28 million new infections at a cost of USD 3,900 for each life saved. Extending maternal and newborn health coverage to $95 \%$ of the poorest countries could save over 100 million lives at a cost of USD 390 for each life saved. Nevertheless, we argue that there are a number of justifications for spending money on HIV/AIDS (and other infectious diseases). First, since HIV/AIDS is infectious, HIV prevention saves more than the life of the person who avoids HIV infection. Second, prevention targeted at vulnerable groups is a cost effective means to reduce disease propagation among the general population. Third, where HIV/AIDS funding is spent to strengthen general healthcare systems, the benefits are not limited to HIV/AIDS alone.

\subsection{The Political Economy of Patents and Global Health Threats}

In Chap. 5 we examine the problem of regulatory capture through the lens of national and international regulation of pharmaceutical patents. National regulatory capture can lead to de facto international regulatory capture when the national 
government in question has disproportionate influence in international organizations, such as the World Bank, or disproportionate bargaining power in international negotiations, such as trade negotiations at the WTO or in regional trade agreements. The source of the influence or bargaining power can include the percentage of world trade of a country, the size of its market, its spending power with respect to foreign aid, the size and percentage of its monetary contributions to international organizations and its ability to facilitate membership in a desirable economic group (such as the European Union or WTO). The degree of bargaining power or influence for the same national government can vary with the context. For example, the bargaining power of the United States is greater in free trade negotiations with small developing countries than it is in the WTO context, where the bargaining power of the United States is offset by the bargaining power of the European Union or other coalitions of influential countries. Where an industry succeeds in capturing the regulatory process of one or more national governments, that regulatory capture can lead to the indirect capture of international regulatory processes, leading to international rules that favor the industry at the expense of global welfare.

In Chap. 5, we show how the threat of compulsory licenses in the United States and Canada, to address real and imagined threats of anthrax, respectively, undermined their initial bargaining position in WTO negotiations on compulsory licensing of pharmaceuticals in developing countries. The severity of the HIV/AIDS crisis in many parts of the developing world, combined with the duplicitous policy of Canada and the United States regarding patent rights, prompted several developing countries to adopt a common position calling for clarifications to the rights of governments to issue compulsory licenses to protect public health and, in particular, to promote access to medicines for all. The resulting Declaration on the TRIPS Agreement and Public Health also identified a gap in the Agreement on Trade-Related Aspects of Intellectual Property Rights (TRIPS), under which only countries with adequate pharmaceutical manufacturing capacity could in practice exercise the right to issue compulsory licenses on pharmaceutical products. Two years of multilateral negotiations on this issue ultimately led to a decision to amend the TRIPS Agreement (known as the Paragraph 6 Decision), but it took two more years to adopt the amendment formally and it has yet to be adopted by the two-thirds of the WTO Members required for it to enter into force. However, the most interesting aspect of these negotiations was the extent to which the Pharmaceutical Research and Manufacturers of America (PhRMA), which lobbies the US government on behalf of its member companies, succeeded in dictating the US government's position in the negotiations.

This instance of international regulatory capture was later followed by two other examples, in several free trade negotiations between the United States and developing countries and in the exercise of the US Trade Representative's authority to identify and apply political pressure to countries that are considered to be undermining US commercial interests. For example, the Central America-Dominican 
Republic-United States Free Trade Agreement (CAFTA-DR) not only created new obstacles to compulsory licensing of pharmaceutical products in several small developing countries, but also overrode the clarifications to the rights of governments that were achieved in the WTO negotiations. When Thailand - a country that did not negotiate this type of free trade agreement with the United States exercised its rights under WTO law to issue compulsory licenses on some pharmaceutical products (including antiretroviral drugs for its HIV/AIDS treatment program), the US Trade Representative placed Thailand on its priority watch list of countries and characterized the Thai government's decision as "further indications of a weakening of respect for patents". This kind of political pressure from the governments of the major pharmaceutical companies discourages the use of compulsory licensing to increase affordable access to medicine in developing countries and undermines the international rule of law.

In Chap. 5 we show why strong patent rights for pharmaceutical products in developing countries are not necessary to provide research incentives to invent new medicines. We also argue show why parallel imports of cheaper drugs from developing countries are unlikely to undermine research incentives in developed country markets. We then analyze whether patents are necessary for innovation to occur and argue that patent rights in fact have the effect of stifling innovation by providing an incentive to patent holders to invest in legal action to extend the life of their patents and to prevent others from developing new innovations. In economic terms, this is an inefficient way of allocating economic resources. Striking the right balance between incentives to invent new medicines and affordable access to those medicines is a key issue in addressing global diseases.

\subsection{Global Diseases, Global Patents and Developing Countries in WTO Law}

Chapter 6 analyzes the key patent provisions of the WTO TRIPS Agreement, in light of the relevant WTO jurisprudence that has interpreted these provisions and other WTO provisions that relate to the special and differential treatment of developing countries in the WTO system.

Governments grant patents to inventors on the national level, which means that they only have legal effect in the jurisdictions where the application for a patent has been granted. One of the conditions for granting a patent is that the inventor disclose the data used in the producing the invention. TRIPS established minimum standards for the protection of intellectual property rights in the national laws of WTO Members. TRIPS requires that patents be granted for a minimum of 20 years and that they provide patent owners with the exclusive right to prevent third parties from making, using, selling or importing a patented product without the owner's consent. However, TRIPS allows exceptions to these patent rights, including the right of governments to issue compulsory licenses under certain conditions. A compulsory license authorizes a third party to produce and sell the 
invention without the patent owner's consent. This exception plays a key role in balancing the rights of patent owners against the needs of consumers of patented products. The right to issue a compulsory license on a patented drug provides countries with bargaining power to extract price concessions for patented drugs or to issue compulsory licenses if price negotiations fail. However, this bargaining power applies only to countries that have the manufacturing capacity to produce generic drugs, since the generic drugs must be used to predominately supply the national market of the country that issues the compulsory license. Countries that lack domestic manufacturing capacity would need to be able to import generics manufactured under compulsory licenses in other countries in order to enjoy a comparable level of bargaining power. The Paragraph 6 Decision established rules to allow this to happen.

The Paragraph 6 Decision waives an exporter's obligation to supply predominantly its domestic market, enabling any country with manufacturing capacity to issue a compulsory license to produce generic drugs for export to countries that have insufficient or no manufacturing capacity, subject to several conditions. No formal restriction on the countries that are eligible to import exists under the Paragraph 6 system. All WTO members, other than least-developed countries, are required to notify the WTO of their intention to use the Paragraph 6 system. Some countries have made a commitment not to use the Paragraph 6 system as importers, while several others have committed to using the system as importers only in situations of national emergency or extreme urgency. The latter have agreed, in effect, not to use the system simply to lower the general cost of purchasing medicine for public health care systems. No restrictions exist regarding the countries that are eligible to export.

The Paragraph 6 system does not apply to countries that have sufficient manufacturing capacity to issue compulsory licenses to meet the needs of their own populations. The question in a given case is whether the importing country has manufacturing capacity for the pharmaceutical product in question. For example, countries like China, India and Brazil, if they lack capacity for a particular medicine, could use the Paragraph 6 system to import drugs from generic manufacturers in other countries. However, where developing countries do have manufacturing capacity, they will have to determine whether and how to use compulsory licensing to reduce the cost of providing treatment by issuing licenses to their own generic manufacturers. When a country issues a compulsory license to its own generic drug manufacturers to serve its own market, the Paragraph 6 Decision will not apply.

Among the policy objectives of the TRIPS Agreement is to balance intellectual property rights against development needs. In WTO law more generally, there are numerous provisions that provide for differential treatment based on the level of development of WTO members. We make a distinction between global diseases (diseases that are prevalent in both developed and developing countries, such as HIV/AIDS) and neglected diseases (developing country diseases that are not 
prevalent in developed countries, such as malaria). The economic issues are different for these two categories, because the markets for drugs that treat the diseases are different. We argue that global patents not necessary to provide research incentives for neglected diseases, nor are global patents necessary to provide research incentives for global diseases. Moreover, drug patents have neither a positive economic impact on developing countries nor meet their development needs.

We propose to eliminate the obligation of eligible developing countries to provide patent rights for pharmaceutical products, through waivers for developing countries and extended transition periods for least-developed countries. In this regard, Chap. 6 proposes a categorization of the WTO membership in the form of an index that can be used to achieve a more equitable balance between the rights of producers and users on a market-by-market basis. This proposal is grounded on economic considerations and takes into account the need to apply a systematic international standard to determine the particular needs of developing countries. The proposed index addresses the needs of a country not just based on its level of poverty, but also based on a threshold level of infection rate for a particular disease. The index serves to promote affordable access to medicine using criteria that are tailored to address the specific circumstances surrounding global or neglected diseases.

The applicability of the index to diseases and pandemics other than HIV/AIDS depends on the speed at which the disease spreads. In the case of other slowingmoving global diseases, such as tuberculosis and diabetes, the index is applicable because the disease rate can be determined. In the case of a fast-moving global disease, such as SARS or influenza, or the use of biological agents in war or terrorism, such as anthrax, governments may wish to stockpile medical treatment before the disease occurs. In these circumstances, the disease rate cannot be determined before the government needs to acquire the necessary medical treatment. However, WTO members can exercise their right to issue compulsory licenses to address a national emergency or other circumstances of extreme urgency under TRIPS Article 31 or the Paragraph 6 System or use the threat of a compulsory license to expand production or to lower the cost of the drugs that they need to stockpile.

\subsection{Bilateral and Multilateral Financing of HIV/AIDS Programs}

Chapter 7 examines the activities of the World Bank, the International Monetary Fund (IMF), the Global Fund, bilateral donors and the private sector. We examine the relationships among bilateral donors and international organizations, what distinguishes their roles in the global HIV/AIDS pandemic and the extent to which their activities overlap. We show how funding strategies and parameters affect the effectiveness of AIDS funding in preventing transmission and providing treatment. 
Multilateral institutions, such as the World Bank, the IMF and the Global Fund, and bilateral donors, including non-governmental organizations (NGOs) and national governments, need to coordinate and harmonize their policies and financing conditions in order to reduce the administrative burden on recipients and in order to avoid imposing conflicting conditions on recipients. Donors also need to be careful with respect to the role assigned to the private sector in delivering aid, in order to avoid the unnecessary diversion of funds away from the core goal of healthcare.

The global response to the HIV/AIDS pandemic has highlighted the need to strengthen healthcare infrastructure in developing countries. It is important to address the HIV/AIDS pandemic in a way that strengthens the ability of national governments and multilateral organizations to address health concerns more generally. Particularly in the case of fast-moving infectious diseases, equitable and effective distribution should be paramount, since such diseases are unlikely to respect socio-economic boundaries.

The global business community has an important role to play in addressing global diseases. It is important to integrate health issues into the overall business strategy of firms. In addition, there is a need to standardize best practices on a more systematic basis and to create incentives for those best practices to be adopted by suppliers and business partners of global companies.

\subsection{The Successes and Failures of Global Health Organizations}

Chapter 8 examines the activities of the WHO, UNAIDS, Médicins sans Frontières (MSF), the US President's Emergency Program for AIDS Relief (PEPFAR) and the CDC. The ineffectiveness of the WHO in addressing the HIV/AIDS pandemic and the advent of SARS and H5N1 influenza highlighted the need for reforms to make the WHO a more effective multilateral health institution. In 2005, reforms to the WHO International Health Regulations (IHR) enhanced the ability of the WHO to coordinate and implement a global response to global diseases and future pandemics. The effectiveness of the IHR, which entered into force in 2007, has also been enhanced by the advent of modern communications technologies, which facilitate the dissemination of news on outbreaks of contagious diseases. The IHR focus on fast-moving contagious diseases and reflect the core competencies of the WHO. While the IHR have norms that discourage the use of disproportionate trade and travel restrictions in response to disease outbreaks, health-related trade restrictions are regulated by the WTO. However, the risk assessments conducted by the WHO under the IHR are likely to influence the application of WTO rules to such cases.

UNAIDS has filled the gaps left by the WHO with respect to the HIV/AIDS pandemic, but the creation of such disease-specific agencies is not the best approach to addressing fast-moving global diseases. Moreover, even the creation of 
UNAIDS has been insufficient to provide adequate multilateral leadership on HIV/AIDS within the UN system.

MSF has moved in to fill the gaps left by the UN system. However, while MSF has filled an important need, its withdrawal from collective efforts sets an unfortunate precedent in an environment where a multiplicity of players and approaches requires greater harmonization and coordination of efforts in order to ensure the efficient use of resources. Nevertheless, the creation of UNAIDS and the approach of MSF both serve to highlight the need for ongoing reforms to improve the effectiveness of global health institutions and have led to innovative approaches that may serve as models for such reforms.

PEPFAR has injected much-needed funding for HIV/AIDS. However, the policies that have been imposed on funding for treatment have favored the commercial interests of the US pharmaceutical industry, thereby undermining the goal of increasing access to treatment. The policies imposed on funding for prevention have favored the ideological interests of conservative Christian organizations in the United States, thereby undermining the goal of effective, science-based prevention efforts. While the use of funding should be monitored to ensure its effective use, substituting science-based strategies with strategies that cater to the domestic political interests of donor governments can hamper efforts to address pandemics effectively.

The CDC is part of the US Department of Health and Human Services. In addition to its work in the United States, the CDC is involved in global health activities. The CDC is a recognized source of expertise, particularly in responding to outbreaks of infectious diseases around the world. The CDC responds to outbreaks of infectious diseases by deploying staff, monitoring the spread of disease and training public health staff from other countries. The CDC is also a valuable source of research and publications on public health issues. Its work outside the United States, with national partners and the WHO, represents a valuable contribution to global health and a recognition of the interconnectedness of global health issues.

\subsection{Prevention, Treatment and Human Rights}

In Chap. 9, we emphasize the importance of integrating prevention, treatment and human rights to manage HIV/AIDS effectively. The primary reason that human rights need to be addressed in conjunction with prevention and treatment is because discrimination keeps people away from both prevention and treatment programs. Moreover, stigma and discrimination have reduced the effectiveness of prevention programs by excluding vulnerable groups. The less effective prevention programs are, the more treatment is required and the less affordable the goal of universal access to treatment will be. 
Global access to antiretroviral therapy for people living with HIV/AIDS has been scaled up significantly in recent years. Many developing countries now have universal access to treatment, including low-income countries, such as Rwanda, and middle-income countries, such as Thailand and Brazil. However, prevention needs to be scaled up considerably in order to make universal access to treatment an affordable goal on a global scale. Without adequate prevention, new infections will rise and millions more people will need treatment. The increase in new HIV infections in several high-income countries highlights the need for effective prevention programs in all countries. This requires an evidence-based focus on highrisk groups and locations to achieve the best possible results, including programs for commercial sex workers and needle exchange programs. The need to focus prevention efforts on the most vulnerable groups remains an issue in both developed and developing countries. Proven HIV prevention strategies for sexual transmission, blood-borne transmission, mother-to-child transmission, as well as social strategies to reduce vulnerability to HIV/AIDS, need to be focused according to the specific nature of the epidemic in different settings. Strategies that increase stigma and discrimination against vulnerable groups ignore the fact that people at high risk of contracting HIV/AIDS do not live in isolation from the general population.

With the advent of triple combination therapy, the focus has shifted from the effectiveness of treatments for HIV/AIDS to the cost of making effective treatments accessible. This is why the issue of drug patents has become so important. However, increasing the number of people receiving treatment will require addressing the capacity constraints of treatment providers, which include limited health infrastructure and human resources, management capacity and the ability to identify new patients through testing and counseling. While high-income countries and middle-income countries with low prevalence rates are in a position to pay for HIV/AIDS treatment, middle-income countries with high prevalence rates and most low-income countries are not. Low-income countries with high prevalence rates in particular will have to depend on external funding sources, such as PEPFAR and the Global Fund, to expand access to treatment and then to maintain treatment.

Scientists have been trying to develop an HIV vaccine for more than 20 years, but without success. Moreover, HIV/AIDS vaccine trials to date reveal a pattern of development of potential vaccines not in the subtypes where the needs are the greatest, but where the biggest monetary rewards are expected. The economics of HIV/AIDS vaccines suggest that funding for vaccines for the worst-effected countries are unlikely to come from the private sector.

HIV/AIDS-related human rights are the area where the least progress has been made and need to become a central focus in the global fight against HIV/AIDS. This requires the reform and repeal of laws that discriminate against vulnerable groups and HIV-positive people, and the introduction or strengthening of laws that prohibit discrimination against vulnerable groups and HIV-positive people. For 
example, laws that prohibit sexual acts between consenting adults in private, laws prohibiting sex work that involves no victimization and laws prohibiting measures such as needle exchange create obstacles to treatment and prevention. Laws and cultural traditions in some countries increase women's vulnerability to HIV/AIDS, either within marriage or by forcing them to support themselves and their children as sex workers. Laws that criminalize HIV transmission and travel restrictions based on HIV status discriminate directly against people with HIV/AIDS and often ignore scientific evidence. On the plus side, courts in a variety of countries have applied constitutional law, international law and other legislation to uphold the rights of people living with HIV/AIDS with respect to employment and access to HIV-related medical care and treatment.

The United Nations International Guidelines on HIV/AIDS and Human Rights acknowledge the inherent limitations in using law reform to enhance human rights. The effectiveness human rights laws depend on the strength of the legal system in a given society and on the access of its citizens to the system, both of which vary considerably from one country to the next. Moreover, the law cannot serve as the only means of educating, changing attitudes, achieving behavioral change or protecting people's rights. Nevertheless, since laws regulate conduct between the State and the individual and between individuals, they can either support or undermine the observance of human rights, including HIV-related human rights.

\subsection{Increasing the Effectiveness of Global Disease Management}

Understanding past outbreaks of diseases can lead to new public health measures and other interventions to more effectively address existing diseases and to better prepare the world for future pandemics. While medicine and science have a crucial role to play in addressing pandemics, whether slow-moving (like HIV/AIDS) or fast-moving (like influenza), the social, legal, political, financial and economic ramifications of pandemics can not be ignored. Well-considered social, legal, political and financial strategies are essential in order to address any pandemic effectively, but they are particularly important when it comes to addressing fastmoving pandemics.

International human rights law and international health law are far less developed and much less effective than international trade law. However, as we show in Chap. 4, global pandemics are also of great importance to economic growth. The key difference between international trade and pandemics is that the former is a positive force for economic growth, while the latter has a negative impact. International trade raises standards of living, whereas pandemics lower standards of living and the length and quality of life. If economic importance is the key reason for having effective global policies, laws and institutions, then the further development an effective global framework to address the negative consequences of pandemics should be given much greater priority. 


\section{References}

Billings M (1997) The Influenza Pandemic of 1918. http://virus.stanford.edu/uda/. Accessed 6 September 2007

Dunham W (2007) Virulent form of cold virus spreads in U.S. Reuters, 15 November 2007

Gao F, Bailes E, Robertson DL, Chen Y et al. (1999) Origin of HIV-1 in the chimpanzee Pan troglodytes troglodytes. Nature 397:436-444

McPherson S (2007) All eyes on Pakistan as H5N1 H2H transmission grows more probable. http://www.scottmcpherson.net/journal/2007/12/14/all-eyes-on-pakistan-as-h5n1h2h-transmission-grows-more-pro.html. Accessed 14 December 2007

Nebehay S (2007) Mixed scenario seen behind Pakistan birdflu spread. http://www. reuters.com/article/latestCrisis/idUSL18866730. Accessed 19 December 2007

Rosenthal E (2007) As Earth Warms Up, Tropical Virus Moves to Italy. http://www. nytimes.com/2007/12/23/world/europe/23virus.html?hp. Accessed 23 December 2007

Sherman IW (2007) Twelve Diseases That Changed Our World. American Society for Microbiology Press, Washington, DC

Taubenberger JK, Morens DM (2006) 1918 Influenza: The Mother of all Pandemics. Emerging Infectious Diseases. http://www.cdc.gov/ncidod/EID/vol12no01/05-0979.htm. Accessed 23 October 2007

Vandamme AM et al. (2003) Tracing the origin and history of the HIV-2 epidemic. Proceedings of the National Academy of Sciences of the United States of America 100(11): 6588-6592

Waters J (2007) Bird flu could have become worldwide pandemic: study. http://www. abc.net.au/news/stories/2007/08/31/2021231.htm. Accessed 31 August 2007

Wolfe ND, Switzer WM, Carr JK et al. (2004) Naturally acquired simian retrovirus infections in Central African Hunters. The Lancet 363:932

Zhou T, Korber B, Nahinias AJ (1998) An African HIV-1 sequence from 1959 and implications for the origin of the epidemic. Nature 391:594-597 